\author{
Reseña \\ wen

\section{Sánchez, Alfredo. 2018. La música de acá. Crónicas de la Guadalajara que suena. Guadalajara: Universidad de Guadalajara}

Adrian Acosta Silva

Lo característico del verdadero músico es no componer ninguna partitura, no tocar ningún instrumento y despreciar

a los virtuosos

Gustave Flaubert, Diccionario de los lugares comunes.

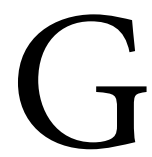

uadalajara es una ciudad compleja, múltiple, heterogénea. Lo ha sido, lo es y seguramente lo seguirá siendo. Los clichés vernáculos, el folklorismo de postal, los lugares comunes que habitan la imagen de la ciudad, del territorio y sus habitantes, son ejercicios reduccionistas, absolutamente inútiles e insuficientes para comprender la variedad y densidad de las prácticas culturales de una metrópoli que rebasó el año pasado la cifra de los cinco millones de habitantes y que ha sido capaz de absorber, ya, a ocho municipios conurbados. Cualquiera que afirme que "conoce" la ciudad es un demagogo, un farsante o un político. Sólo algunos, con prudencia reflexiva, han reconocido el desafío que implica descifrar y caracterizar las múltiples facetas culturales del "animal" metropolitano que es hoy la capital jalisciense.

La lectura del libro que nos ofrece Alfredo Sánchez confirma la necesidad de usar los anteojos de la cautela para tratar de entender la vida cultural tapatía, esa compleja dimensión simbólica de la vida social. Se trata de un texto sin pretensiones académicas (afortunadamente) sino estrictamente periodísticas, un conjunto de crónicas y relatos periodísticos minimalistas, centrados en la vida de algunos de los personajes que han nutrido la vida cultural tapatía de los últimos cincuenta años. Buen representante del periodismo cultural, locutor, coordinador y productor de programas radiofónicos universitarios y no

1- Nacionalidad: Mexicana. Grado: Doctorado. Especialización: Ciencias sociales. Adscripción:Universidad de Guadalajara. Correo electrónico: aacosta@cucea.udg.mx. ORCID: http://orcid.org/0000-0003-2312-8990 
universitarios, músico destacado, cómplice frecuente de otros músicos, de pintores, escultores, teatreros, editores de libros, fotógrafos, ceramistas, galeristas, funcionarios culturales, el autor conoce como muy pocos las experiencias, los lugares, los actores y representantes de una vida cultural que es mucho más diversa y compleja de lo que comúnmente se cree.

Ya en De memoria. Crónicas (Rayuela, Guadalajara, 2013), el conocido conductor del programa "Señales de Humo" (que durante más de una década coordinó en Radio U. de G.), nos había adelantado la orientación del libro que ahora presentamos. Ahí, reunió sus relatos y crónicas sobre distintos proyectos, experiencias, lugares y personajes de la vida cultural tapatía, entre los que se encontraban textos sobre Reynaldo Díaz Vélez (el “Tucky”, ya fallecido, y guitarrista de los Spiders), sobre Gerardo Enciso o sobre Julio Haro (también ya fallecido, compositor principal y voz cantante del grupo El Personal). Ahora, 18 personajes de la música local son entrevistados en La música de acá. Son retratos hechos a mano, surgidos fundamentalmente desde la admiración, como confiesa desde el principio el autor, un criterio legítimo para elegir a quienes se puede o se dejan entrevistar. Cinco de ellos nacieron entre 1920 y 1940 , cuatro en la década de los cuarenta, seis de los cincuenta y tres, los más jóvenes de los entrevistados, pertenecen a los años sesenta. Es decir, encontramos entre los personajes que desfilan en las páginas del libro, músicos que fallecieron a los 92 años (Domingo Lobato), y músicos que tienen hoy 54 años (Carlos Sánchez Gutiérrez). En su conjunto son voces que pertenecen a distintas generaciones de músicos que han vivido en Guadalajara a lo largo de más de medio siglo y que configuran un buen mapa de las sensibilidades y sonidos que han circulado por estas tierras mojadas.

Los entrevistados importan por lo que son, o por lo que fueron (como en el caso de Lobato, o de las recientemente fallecidas, como las maestras Carmen Peredo, o Leonor Montijo), pero importan también por lo que representan: trayectorias vitales individuales inevitablemente unidas a espacios físicos concretos: la Escuela de Música de la U. de G., el Lucifer - un mítico congal rockero ubicado en el centro histórico de la ciudad-, el Copenhagen 77, centros culturales como La Puerta, La Peña Cuicacalli, más recientemente el Barba Negra o El Rojo Café. En esos espacios, pero también en las calles, las cocheras y las casas de los entrevistados, se configuraron atmósferas culturales adecuadas a los distintos espíritus de época que poblaron la música en Guadalajara desde los años cincuenta hasta finales del siglo pasado.

Otro elemento importante del libro es la diversidad de los músicos incluidos en sus entrevistas. De la música clásica al jazz, del rock al blues, de quienes fueron rigurosos formadores académicos de varias generaciones de músicos profesionales, hasta ejecutantes, compositores y cantantes formados en las aguas revueltas de la lírica popular, lo que tenemos en el libro es un muestrario de la educación sentimental de varias generaciones de músicos que hicieron de Guadalajara su lugar de residencia, su espacio vital, cotidiano, el lugar desde el cual sus convicciones estéticas, intereses intelectuales y pasiones personales se conjugaron para forjar trayectorias destacadas en la música local, nacional y hasta internacional. Sí, como señalara Flaubert en el siglo XIX, la música "suaviza las costumbres", la que se ha producido y escuchado por acá forma parte de la banda sonora que ha acompañado las transformaciones de la ciudad, el ruido de fondo de los procesos de "destrucción creativa" que han alterado los hábitos, los paisajes y las costumbres de los tapatíos desde los años setenta del siglo pasado.

Es interesante el hecho de que muchos de los entrevistados se hicieron tapatíos por adopción. Sonorenses, morelenses, chilangos, potosinos, gringos, llegaron a Guadalajara a vivir en distintos momentos y circunstancias, junto con quienes nacieron en Jalisco pero no en Guadalajara (provenientes de La Barca, 
Tequila o San Martín Hidalgo). La ciudad abierta que ha sido siempre la capital tapatía se confirma con las historias de vida de los forasteros que por decisión o por accidente llegaron a una ciudad que para 1970 apenas rebasaba su primer millón de habitantes. Junto a esos forasteros, desfilan también en las entrevistas oriundos del barrio de Analco (el Willow y Chepe Pulido). Esa mezcla de lugares y orígenes muestra el carácter diverso de los estilos que llegaron a poblar la ciudad y mezclarse con corrientes culturales y otros géneros musicales más o menos dominantes en la escala local.

La música culta siempre ha tenido una presencia importante en la ciudad, una clara herencia de la Guadalajara aristocrática de los años treinta y cuarenta. Como señala en su entrevista la maestra y concertista Peredo, "estudiar piano era una cosa de clase", un símbolo de distinción. Pero en los años 50 y 60 , en el contexto de la segunda modernización mexicana -la primera había sido, con todo la modernización porfiriana-, con la irrupción de géneros como el jazz y la "música de orquesta", los músicos clásicos aprendieron que había que diversificar sus habilidades para sobrevivir como tales. El Maestro Arturo Xavier González fue quizá el que mejor atendió las señales del cambio, de la transición de la música culta de chelos, pianos, violines y trombones hacia la hibridación con la música popular que se tocaba con guitarras eléctricas, órganos y trompetas en salones de baile, fiestas de quinceañeras, bautizos, bodas, y celebraciones de cualquier otro tipo.

Pero los años sesenta y setenta fueron el auge del rock y el blues en Guadalajara. La Revolución de Emiliano Zapata, Spiders, 39.4, La Fachada de Piedra, Toncho Pilatos, primero, y luego, en los ochenta, destacadamente El Personal o Escalón -agrupaciones en las que participó el propio Alfredo Sánchezconfiguraron trayectorias musicales que alimentaron el carácter francamente escéptico, bastardo, de la "identidad" musical tapatía. Back o Nasty Sex, por ejemplo, sonaban en San Andrés, en Analco, en Oblatos (barrios situados de la Calzada independencia "pa'llá", según las viejas costumbres tapatías), pero también en Jardines del Bosque o en Providencia (colonias ubicadas de la calzada "pa cá"), junto a las canciones de Javier Solís, de Vicente Fernández, el Mariachi Vargas de Tecalitlán, Los Terrícolas, Los Ángeles Negros, Mickey Laure o, por supuesto, el Príncipe de la Canción. Es un auténtico misterio cómo sobrevivieron los músicos entrevistados en un contexto dominado abrumadoramente por la música comercial local y extranjera, con pocos espacios para tocar en vivo, y con las permanentes reservas de compañías discográficas nacionales para promover los sonidos locales.

Canal 58 y Stereo Soul eran estaciones de radio populares que por esos años competían, o coexistían, con la estación que se promocionaba como La Voz de Guadalajara, o como la Fórmula Melódica que se escuchaba en parques públicos, plazas o moteles de paso en Zapopan, Tlaquepaque o Guadalajara. La música clásica dejó de ser dominante en la radios públicas como la de la U. de G., para incorporar el jazz y el rock como géneros dominantes a finales de los años ochenta, en un esfuerzo tardío por penetrar en los nuevos públicos jóvenes de la ciudad. La música de las generaciones se amontonaba en la escena local y muchos de los personajes que destacaron en esos procesos de adaptación y transformación se convirtieron por razones de la voluntad, del azar o del destino en protagonistas de esas épocas y estilos. Las maestras Peredo y Montijo, Lobato, o Manuel Cerda en la vertiente clásica de la composición y ejecución; Ernesto Cano como la coexistencia vital entre lo clásico y el jazz; Carlos de la Torre o Javier Soto en el jazz más puro; y Guillermo Brizio, Enrique Sánchez Ruiz, el Chepe Pulido, Tony Vierling, Genaro Palacios, o Carmen Ochoa, en el flanco del rock y del blues que haría de Guadalajara un referente nacional.

Es un acierto que el autor haya incluido en el libro las entrevistas a quienes generalmente nunca apare- 
cen en público: los ingenieros de sonido. Personajes poco conocidos (y reconocidos), profesionales de estudios de grabación y presentaciones en vivo, los ingenieros son parte de la plomería indispensable para que existan estaciones, discos, mezclas de sonidos, efectos especiales, ritmos, mezclas, que finalmente permiten confeccionar una obra musical. Raúl Cuevas, Arturo Perales y Sergio Naranjo son tres de esos personajes cuyas trayectorias no solo acompañan sino que también construyen vidas paralelas a la de los compositores y cantantes que se dedican al oficio. Su contacto profesional, laboral y frecuentemente amistoso con autores y compositores nos ayuda a comprender un poco mejor la química y la física vital de la música que se produjo en las décadas pasadas y se produce aún en Guadalajara.

Varias pistas se desprenden de los itinerarios y experiencias vitales de los entrevistados, que van más allá de las anécdotas personales y de las inevitables subjetividades que habitan sus relatos. Pero el anecdotario, los dichos, las frases de los entrevistados le ponen sal a La música de acá. Rescato solo dos. En una, relatada por Tony Vierling (vocalista y guitarrista de los Spiders), la presencia de Bob Dylan recargado en una de las columnas del "Lucifer", escuchando a Spiders. La otra la relata Jorge Soto: la presencia intimidante y sorpresiva de un personaje siniestro y sus inevitables guaruras en el Copenhagen, bebiendo whisky y escuchando jazz: Miguel Angel Félix Gallardo, el líder del cártel de Sinaloa en los tiempos de Don Neto y de Rafael Caro Quintero.

El texto reúne con fortuna un conjunto de contribuciones testimoniales y biográficas importantes para construir una suerte de sociología cultural de la sociedad o sociedades tapatías del último medio siglo. Las entrevistas trabajadas y logradas por el autor a lo largo de varios años, para ser transcritas, revisadas y publicadas hoy en forma impresa, es un buen regalo para los lectores interesados en el pasado reciente de la vida cultural local. Después de todo, la música tiene siempre un sonido local propio, con actores, protagonistas y espectadores específicos, que vuelve distinto lo nacional y lo universal a través de la imaginación, el oficio y la creatividad de músicos locales. Parafraseando al historiador Simon Schama, ese es el poder de la música: su capacidad para asombrarnos, para sorprender a quienes por gusto, por interés, o por los misterios del azar, hemos aprendido a vivir en una ciudad que ha producido algunos de los mejores compositores, bandas y cantantes de la vida cultural nacional. . 